\title{
Hydrogen sulfide from a NaHS source attenuates dextran sulfate sodium (DSS)-induced inflammation via inhibiting nuclear factor-кB
}

\author{
Xi CHEN ${ }^{1,2}$, Xi-shuang LIU $\$ \$ 1,3$ \\ ( ${ }^{1}$ Medical College, Qingdao University, Qingdao 266021, China) \\ ('Department of Gastroenterology, Yantai Municipal Laiyang Central Hospital, Yantai 265200, China) \\ ( ${ }^{3}$ Department of Gastroenterology, the Affiliated Hospital of Qingdao University, Qingdao 266071, China) \\ †E-mail: liunich2015@126.com \\ Received Oct. 11, 2015; Revision accepted Dec. 9, 2015; Crosschecked Feb. 15, 2016
}

\begin{abstract}
This study investigated the alleviating effects of hydrogen sulfide $\left(\mathrm{H}_{2} \mathrm{~S}\right)$, derived from sodium hydrosulfide (NaHS), on inflammation induced by dextran sulfate sodium (DSS) in both in vivo and in vitro models. We found that $\mathrm{NaHS}$ injection markedly decreased rectal bleeding, diarrhea, and histological injury in DSS-challenged mice. NaHS $(20 \mu \mathrm{mol} / \mathrm{L})$ reversed DSS-induced inhibition in cell viability in Caco-2 cells and alleviated pro-inflammation cytokine expression in vivo and in vitro, indicating an anti-inflammatory function for $\mathrm{H}_{2} \mathrm{~S}$. It was also found that $\mathrm{H}_{2} \mathrm{~S}$ may regulate cytokine expression by inhibiting the nuclear factor-KB (NF-KB) signaling pathway. In conclusion, our results demonstrated that $\mathrm{H}_{2} \mathrm{~S}$ alleviated DSS-induced inflammation in vivo and in vitro and that the signal mechanism might be associated with the NF-KB signaling pathway.
\end{abstract}

Key words: Hydrogen sulfide $\left(\mathrm{H}_{2} \mathrm{~S}\right)$, Inflammation, Nuclear factor-kB (NF-kB), Dextran sulfate sodium (DSS) http://dx.doi.org/10.1631/jzus.B1500248

CLC number: R574

\section{Introduction}

Inflammatory bowel disease (IBD) patients suffer from chronic inflammation with the most common symptoms being weight loss, abdominal pain, (bloody) diarrhea, fatigue, and frequently extraintestinal symptoms such as joint pain or skin and eye inflammation (Dubeau et al., 2013; Liu et al., 2014; Mileva et al., 2014; Malago et al., 2015; Xu et al., 2016). Kaplan (2015) reported that the incidence of IBD in the world is continuing to rise, with increasing prevalence in both industrialized and developing countries. While the exact etiology of IBD remains obscure, inflammation has been identified as a factor contributing to disease progression (Hirai and Matsui,

\footnotetext{
¿ Corresponding author

(1) ORCID: Xi-shuang LIU, http://orcid.org/0000-0002-5177-3535

(C) Zhejiang University and Springer-Verlag Berlin Heidelberg 2016
}

2015; Shimshoni et al., 2015).

The nuclear factor- $\mathrm{KB}(\mathrm{NF}-\mathrm{\kappa B})$ signaling pathway has been found to be involved in differentiation, immune response, proliferation, cell adhesion, angiogenesis, oxidative stress, and apoptosis (Watanabe et al., 2015). Compelling evidence indicates that $\mathrm{NF}-\kappa \mathrm{B}$ is associated with various inflammatory diseases, including ulcerative colitis and Crohn's disease (Sun and Zhang, 2007). TLR4/Myd88, an upstream signal of NF- $\mathrm{KB}$, can be activated in response to various inflammatory and infectious diseases. After activation, TLR4/Myd88 mediates the inflammatory response by activating NF- $\mathrm{kB}$ (Cao et al., 2014; Wang et al., 2015). Inhibitors of the NF-kB signaling pathway have been widely used to alleviate IBD (Sunil et al., 2010; McCann et al., 2015).

Hydrogen sulfide $\left(\mathrm{H}_{2} \mathrm{~S}\right)$ is a gaseous molecule with various physiological functions, including neuromodulation, oxidative stress, regulation of blood 
pressure and cardiac function, inflammatory response, cellular energetics and apoptosis (Kabil et al., 2014). The beneficial role of $\mathrm{H}_{2} \mathrm{~S}$ in various inflammatory responses has been validated (Gemici et al., 2015; Howell et al., 2015; Zhang et al., 2015), but there is little reference to the effects of $\mathrm{H}_{2} \mathrm{~S}$, or its mechanisms of action, in IBD. In this study we therefore evaluated the pharmacological effects of $\mathrm{H}_{2} \mathrm{~S}$ from a sodium hydrosulfide (NaHS) source on inflammation and the NF- $\mathrm{kB}$ signal in dextran sulfate sodium (DSS)-induced inflammation in both in vivo and in vitro models of IBD.

\section{Materials and methods}

\subsection{Animal model and groups}

Thirty-two male ICR mice weighing 22-24 g were used in the experiment. Mice were divided into three groups each containing 10 animals: a control group (Cont), a DSS group (DSS), and a NaHS+DSS group (NaHS). In the control group, mice were allowed free access to tap water for drinking. Mice in the other two groups were allowed free access to a 5\% $(0.05 \mathrm{~g} / \mathrm{ml})$ DSS solution supplied as drinking water for $7 \mathrm{~d}$ to induce colonic inflammation. Mice from the NaHS group received freshly prepared NaHS solution (14 $\mu \mathrm{mol} / \mathrm{kg}$; Sigma-Aldrich) via intraperitoneal injection twice a day. Mice in the control and DSS groups received the same volume of sterile saline alone. The NaHS dosage was according to a previous report (Benetti et al., 2013). All mice were housed in polycarbonate cages at room temperature $(25 \pm 3){ }^{\circ} \mathrm{C}$, humidity $(50 \pm 5) \%$, and a 12 -h cycle of light and dark. During the experimental period, all mice were allowed free access to laboratory strip chows.

Afterwards, each mouse was weighed to calculate the average weight gain and then sacrificed. Colonic length and weight were measured. In addition, colonic samples from each mouse were collected and immediately frozen in liquid nitrogen and stored at $-70{ }^{\circ} \mathrm{C}$ for further analyses.

\subsection{Clinical evaluation of DSS colitis}

Rectal bleeding and diarrhea from each mouse were recorded daily. The rectal bleeding was determined using Haemoccult kits (Beckman Coulter, Inc., CA, USA). The score of rectal bleeding was classified as follows: 0 for no blood (normal); 2 for positive haemoccult; and 4 for gross bleeding. The diarrhea score was classified as follows: 0 for well-formed pellets; 2 for pasty and semiformed stools; and 4 for liquid stools (Vlantis et al., 2015).

\subsection{Histomorphometry determination}

Haematoxylin and eosin (HE) staining (Yin et al., 2015b) was used for morphological evaluation after DSS treatment. Briefly, colon samples $(0.5 \mathrm{~cm})$ were kept in $4 \%$ neutral buffered $10 \%$ formalin, processed using routine histological methods and mounted in paraffin blocks. Then $6-\mu \mathrm{m}$-thick sections were cut and stained with HE. All specimens were examined under a light microscope (Nikon, Japan).

The histological examination was performed in a blinded fashion using a scoring system previously validated and described: severity of inflammation (0-3: none, slight, moderate, severe), depth of injury (0-3: none, mucosal, mucosal and submucosal, transmural), crypt damage (0-4: none, basal 1/3 damaged, basal $2 / 3$ damaged, only surface epithelium intact, entire crypt and epithelium lost), and percentage of the involved area $(0-4: 0 \%, 1 \%-10 \%, 10 \%-25 \%$, $25 \%-50 \%, 50 \%-100 \%)$. Total scores, including the individual parameters added together, could range from 0 to 14 .

\subsection{Serum immunoglobulins}

Orbital blood was collected and centrifuged at $3000 \mathrm{r} / \mathrm{min}$ for $10 \mathrm{~min}$ after $4 \mathrm{~h}$ clotting at $4{ }^{\circ} \mathrm{C}$. Serum was separated and stored for further analyses. Assay kits for the analysis of serum immunoglobulins were obtained from Nanjing Jiancheng (China). Serum immunoglobulin A (IgA), IgG, and IgM were determined using an Automatic Biochemistry Radiometer system (Au640, Olympus).

\subsection{Cell culture and treatment}

Human colorectal adenocarcinoma-derived intestinal epithelial cells (Caco-2) (ATCC, Manassas, VA, USA) were grown in DMEM/F12 supplemented with $1 \mathrm{mmol} / \mathrm{L}$ sodium pyruvate, $20 \%$ fetal bovine serum, and $50 \mathrm{U} / \mathrm{ml}$ penicillin-streptomycin. Cells were treated with $2 \%(0.02 \mathrm{~g} / \mathrm{ml})$ DSS for $4 \mathrm{~d}$ to induce inflammation (Nighot et al., 2013). Cell viability was determined by the CKK-8 assay (SigmaAldrich, MO, USA) according to the manufacturer's instructions. Briefly, $8 \times 10^{3}$ cells were seeded in $96-$ well plates. In the following day, cells were incubated 
with $1,5,10,20,50$, and $100 \mu \mathrm{mol} / \mathrm{L}$ NaHS for $2 \mathrm{~d}$ and then assayed.

\subsection{NF- $\kappa B$ activity}

Cellular NF-kB activity after DSS and NaHS treatment was measured via an ELISA kit (Cell Biolabs, USA).

\subsection{Complementary DNA (cDNA) synthesis and quantification of mRNA by real-time PCR analysis}

RNA was isolated from colon and cell tissues with TRIZOL reagent according to the manufacturer's instructions. Synthesis of the first strand (cDNA) was conducted using oligo (dT) 20 and Superscript II reverse transcriptase (Invitrogen, USA).

Primers were designed with Primer 5.0 according to the gene sequence of mouse; the sequences are shown in Table 1. Real-time PCR analysis was conducted according to previous studies (Yin et al., 2013a; 2014). The relative expression of different genes was normalized and presented as a ratio to their expression in the control group.

\subsection{Nuclear protein extraction and Western blot analysis}

Nuclear proteins were extracted using nuclear and cytoplasmic extraction reagents in accordance

Table 1 PCR primer sequences: the forward (F) primers and the reverse $(R)$ primers

\begin{tabular}{cl}
\hline Gene & \multicolumn{1}{c}{ Nucleotide sequences of primers $\left(5^{\prime}-3^{\prime}\right)$} \\
\hline$\beta$-Actin & F: GTCCACCTTCCAGCAGATGT \\
& R: GAAAGGGTGAAAACGCAGC \\
$I L-1 \beta$ & F: CTGTGACTCGTGGGATGATG \\
& R: GGGATTTGTCGTTGCTTGT \\
$I L-6$ & F: TGCAAGAGACTTCCATCCAGT \\
& R: GTGAAGTAGGGAAGGCCG \\
$I L-10$ & F: ACAGCCGGGAAGACAATAAC \\
& R: CAGCTGGTCCTTTGTTGAAAG \\
$I L-17$ & F: TACCTCAACCGTTCCACGTC \\
& R: TTTCCCTCCGCATTGACAC \\
$I F N-\gamma$ & F: ATGAACGCTACACACTGCATCTTGGCTT \\
& R: CCTCAAACTTGGCAATACTCATGAATGC \\
$T N F-\alpha$ & F: AGGCACTCCCCAAAAGAT \\
& R: TGAGGGTCTGGGCCATAGAA \\
$T L R 4$ & F: TTCAGAACTTCAGTGGCTGGATT \\
& R: CCATGCCTTGTCTTCAATTGTTT \\
$M y d 88$ & F: GCATGGTGGTGGTTGTTTCTG \\
& R: GAATCAGTCGCTTCTGTTGG \\
\hline
\end{tabular}

with the manufacturer's instructions (Thermo Fisher Scientific Inc., USA). Western blot was performed (Yin et al., 2015a) and NF-kBp65 (Abcam, Inc., USA) was used as the primary antibody. Rabbit proliferating cell nuclear antigen (PCNA) antibody (Sigma) was used as the nuclear protein loading control. The expression ratio of $\mathrm{NF}-\mathrm{kB}$ was normalized against PCNA.

\subsection{Statistical analysis}

All statistical analyses were performed using SPSS 17.0 software. Group comparisons were performed using analysis of variance (ANOVA) and followed with Tukey's multiple comparison test.

\section{Results}

\subsection{Effects of NaHS on clinical indices in DSS- induced colitis}

DSS treatment significantly reduced final body weight, daily weight gain, and colonic length, and increased colonic weight, rectal bleeding score, and diarrhea score $(P<0.05$; Fig. 1). Although NaHS administration failed to alleviate DSS-dysregulated body weight, colonic length, and colonic weight $(P>0.05)$, it markedly decreased scores for rectal bleeding and diarrhea $(P<0.05)$. HE staining results revealed that DSS caused colonic histological injury which was mitigated by NaHS $(P<0.05)$.

\subsection{Effects of NaHS on inflammatory cytokines in DSS-induced colitis}

Colonic interleukin-1 $\beta$ (IL-1 $\beta$ ), IL-6, IL-10, IL-17, interferon- $\gamma$ (IFN- $\gamma$ ), and tumor necrosis factor- $\alpha(\mathrm{TNF}-\alpha)$ mRNA were measured by reverse transcription (RT)-PCR to evaluate the inflammatory response after DSS treatment in mice (Fig. 2). The results showed that adding 5\% DSS to drinking water induced colonic inflammation in mice evidenced by the upregulation of IL-1 $\beta$, IL-6, IL-10, IL-17, and TNF- $\alpha$ expression $(P<0.05)$. Compared with the DSS group, NaHS administration significantly down-regulated colonic IL-1 $\beta$, IL-17, and TNF- $\alpha$ expression $(P<0.05)$, which indicated an antiinflammatory function for NaHS. 


\subsection{Effects of NaHS on serum immunoglobulins in DSS-induced colitis}

As shown in the Table 2, DSS treatment significantly reduced serum $\operatorname{IgG}$ and $\operatorname{IgA}(P<0.05)$. Although NaHS injection tended to alleviate DSS-induced inhibition of $\operatorname{IgG}$ and $\operatorname{IgA}$ levels, the difference was insignificant $(P>0.05)$.
Table 2 Serum immunoglobulins after DSS exposure

\begin{tabular}{cccc}
\hline Group & $\operatorname{IgG}(\mathrm{g} / \mathrm{L})$ & $\operatorname{IgM}(\mathrm{g} / \mathrm{L})$ & $\operatorname{IgA}(\mathrm{g} / \mathrm{L})$ \\
\hline Cont & $12.93 \pm 1.71^{\mathrm{a}}$ & $12.15 \pm 2.07$ & $8.16 \pm 1.30^{\mathrm{a}}$ \\
DSS & $8.70 \pm 1.56^{\mathrm{b}}$ & $10.67 \pm 1.29$ & $5.12 \pm 0.36^{\mathrm{b}}$ \\
NaHS & $9.15 \pm 2.04^{\mathrm{ab}}$ & $11.17 \pm 1.13$ & $6.29 \pm 0.50^{\mathrm{ab}}$
\end{tabular}

Data are expressed as mean \pm standard deviation (SD) $(n=10)$. Values in the same column with different superscripts are significant $(P<0.05)$ (a)

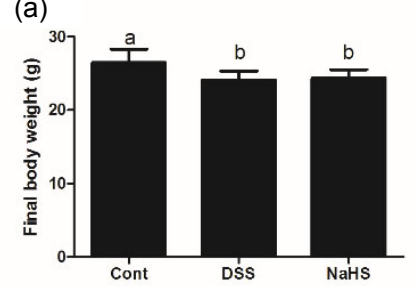

(d)

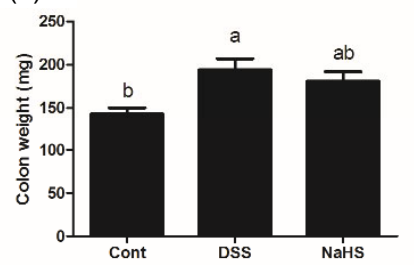

(g)

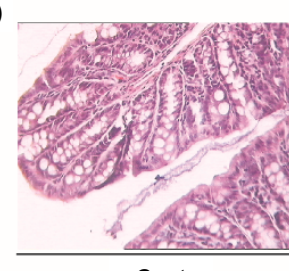

(b)

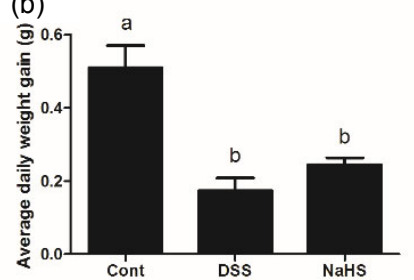

(e)
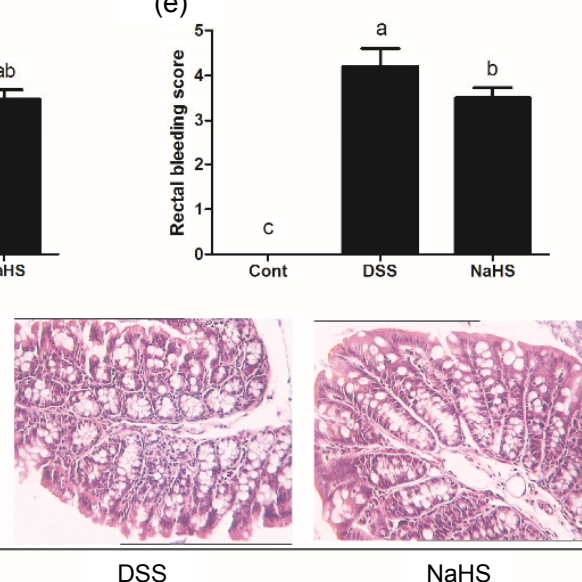

(c)

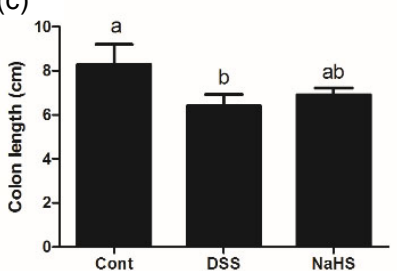

(f)

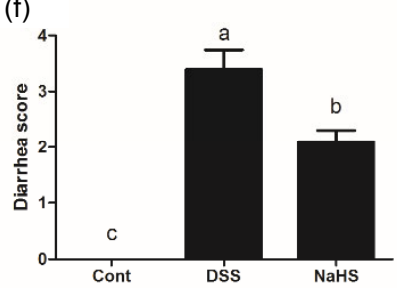

(h)

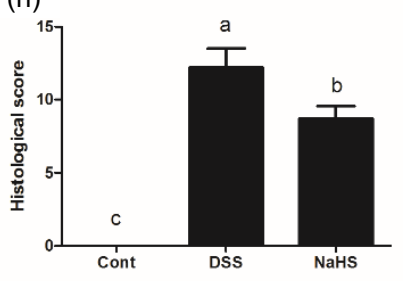

Fig. 1 Effects of NaHS on clinical parameters in DSS-induced colitis in mice

(a) Final body weight; (b) Average daily weight gain; (c) Colon length; (d) Colon weight; (e) Rectal bleeding score; (f) Diarrhea score; (g) HE staining; (h) Histological score. Data are expressed as mean $\pm \mathrm{SD}(n=10)$. Different letters above the columns are significant $(P<0.05)$

(a)

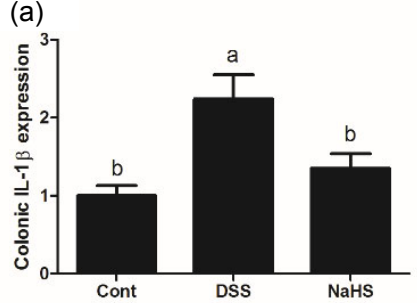

(d)

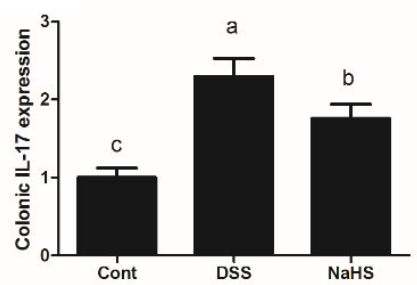

(b)

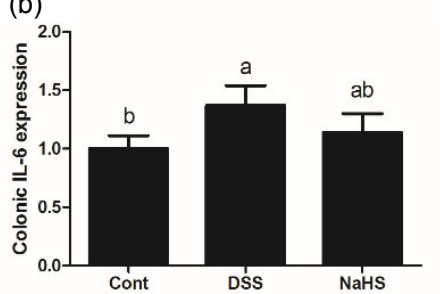

(e)

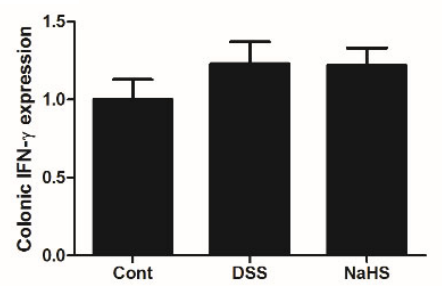

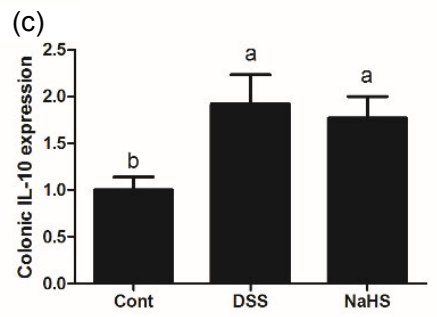

(f)

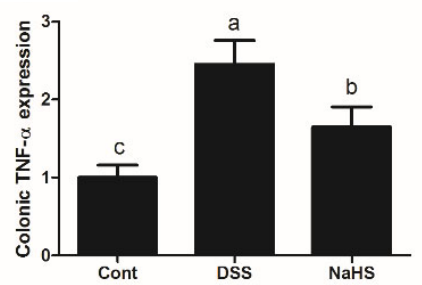

Fig. 2 Effects of NaHS on pro-inflammation cytokine expression in DSS-challenged mice Expression of colonic IL-1 $\beta$ (a), IL-6 (b), IL-10 (c), IL-17 (d), IFN- $\gamma$ (e), and TNF- $\alpha$ (f). Data are expressed as mean \pm SD $(n=10)$. Different letters above the columns are significant $(P<0.05)$ 


\subsection{Effects of NaHS on inflammatory cytokines in DSS-challenged Caco-2 cells}

We examined the role of NaHS in DSS-induced inflammatory response in a cell culture model. Cell viability was measured after treatment with different concentrations of $\mathrm{NaHS}(1,5,10,20,50$, and $100 \mu \mathrm{mol} / \mathrm{L})$. The $2 \%$ DSS inhibited cell viability ( $P<0.05$; Fig. 3 ), whereas $20 \mu \mathrm{mol} / \mathrm{L}$ NaHS markedly reversed this inhibition in Caco- 2 cells $(P<0.05)$. Therefore, $20 \mu \mathrm{mol} / \mathrm{L}$ was used as the experimental dose for other tests.
DSS significantly enhanced IL-1 $\beta$, IL-6, IL-10, IL-17, and TNF- $\alpha$ mRNA abundances in Caco- 2 cells $(P<0.05)$, whereas NaHS alleviated DSS-induced inflammation by downregulating IL-1 $\beta$, IL-17, and TNF- $\alpha$ expression $(P<0.05)$. The in vitro results further validated the anti-inflammatory effect of NaHS.

\subsection{Effects of NaHS on the NF-кB signal in DSS- challenged in vivo and in vitro models}

In the mouse model, DSS significantly activated the TLR4/Myd88 signal compared with the control
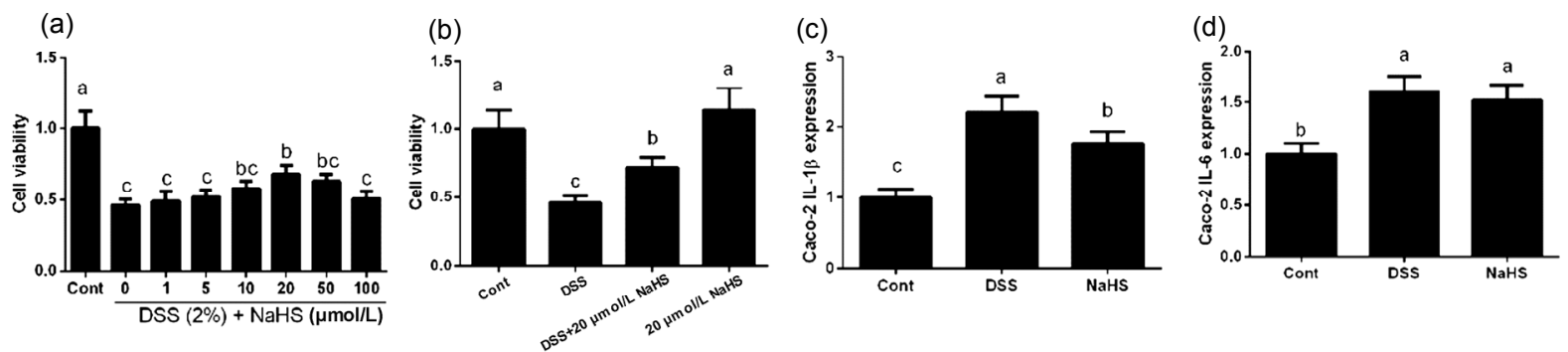

(e)
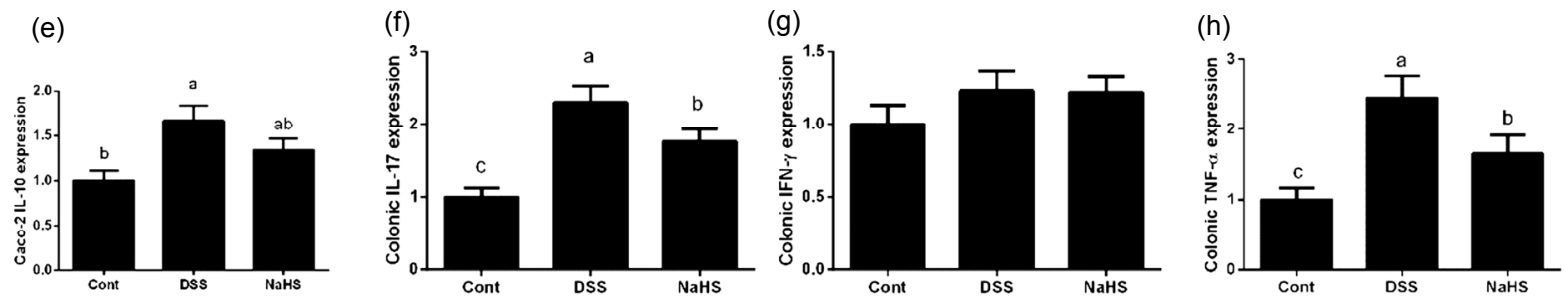

Fig. 3 Effects of NaHS on pro-inflammation cytokine expression in DSS-challenged Caco-2 cells

(a, b) Cell viability; (c) IL-1 $\beta$ expression; (d) IL-6 expression; (e) IL-10 expression; (f) IL-17 expression; (g) IFN- $\gamma$ expression;

(h) TNF- $\alpha$ expression. Data are expressed as mean \pm SD $(n=10)$. Different letters above the columns are significant $(P<0.05)$

(a)

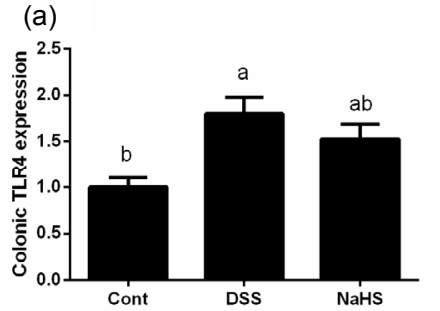

(d)

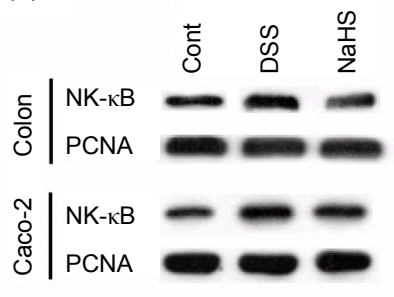

(b)

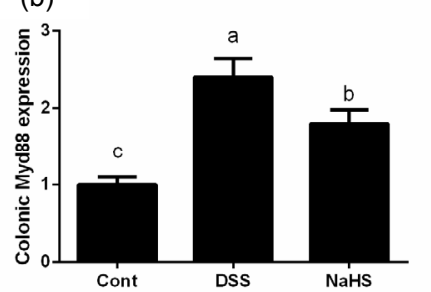

(e)

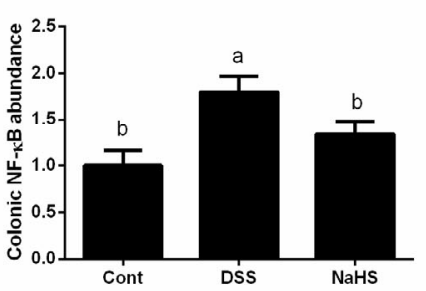

(c)

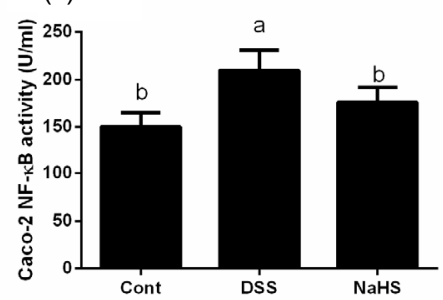

(f)

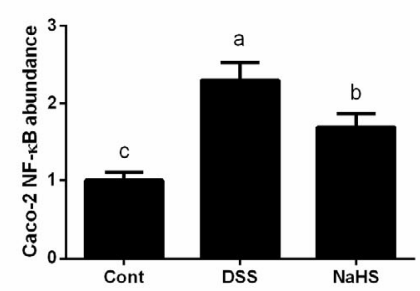

Fig. 4 Effects of NaHS on the NF-кB signal in DSS-induced inflammation in in vivo and in vitro models

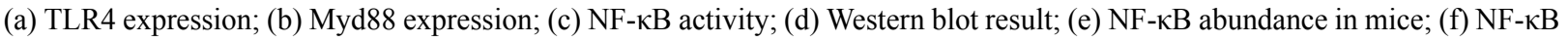
abundance in Caco- 2 cells. Data are expressed as mean $\pm \mathrm{SD}(n=10)$. Different letters above the columns are significant $(P<0.05)$ 
group $(P<0.05$; Fig. 4). Although NaHS failed to down-regulate TLR4 expression, the Myd88 mRNA result demonstrated that DSS markedly enhanced the nuclear translocation of NF- $\mathrm{BB}$ and NaHS inhibited level in the NaHS group was significantly lower than that in the DSS group $(P<0.05)$. The Western blotting result demonstrated that DSS markedly enhanced nuclear translocation of NF- $\mathrm{BB}$ and NaHS inhibited NF- $\kappa \mathrm{B}$ activation $(P<0.05)$. The ELISA and Western blotting results in Caco-2 cells further revealed that NaHS alleviated DSS-induced inflammation by inhibiting the NF- $\kappa \mathrm{B}$ signal in vivo and in vitro.

\section{Discussion}

Accumulating evidence suggests that $\mathrm{H}_{2} \mathrm{~S}$ may serve as an important biological gasotransmitter. $\mathrm{H}_{2} \mathrm{~S}$ at physiological concentrations has been shown to protect cells in retinal neurons and act as a potential therapeutic target for retinal degeneration (Mikami et al., 2011; Eastep and Chen, 2015). $\mathrm{H}_{2} \mathrm{~S}$ also regulates cellular $\mathrm{Ca}^{2+}$ homeostasis in microglial cells (Lee et al., 2006) and protects neurons from oxidative stress injury (Kimura and Kimura, 2004). In immune and inflammatory responses, $\mathrm{H}_{2} \mathrm{~S}$ has been demonstrated to exhibit anti-inflammatory effects in various pathological situations (Bhatia, 2015; Pozsgai et al., 2015). However, some reports suggest that sulfurcontaining compounds, including $\mathrm{H}_{2} \mathrm{~S}$ released from the bacterial metabolism of non-absorbed sulfate, may be the injurious agents in the development of colitis, while Furne et al. (2000) confirmed that blocking fecal release of $\mathrm{H}_{2} \mathrm{~S}$ via bismuth subsalicylate failed to alleviate intestinal inflammation. Although other sources of $\mathrm{H}_{2} \mathrm{~S}$ have been reported in various types of inflammation, this study focused on the effect of $\mathrm{NaHS}-\mathrm{H}_{2} \mathrm{~S}$ on the DSS-induced colonic inflammatory response in in vivo and in vitro models to estimate the beneficial function of $\mathrm{H}_{2} \mathrm{~S}$.

We found that $\mathrm{H}_{2} \mathrm{~S}$, using $\mathrm{NaHS}$ as its source, had a clinically protective effect against DSS-induced colonic injury in mice. $\mathrm{H}_{2} \mathrm{~S}$ markedly decreased rectal bleeding and diarrhea, and alleviated colonic histological injury. A previous study had shown that a marked increase in $\mathrm{H}_{2} \mathrm{~S}$ generation contributes to ulcer healing and inflammation resolution in experimental colitis (Flannigan et al., 2014). Inhibition of endogenous $\mathrm{H}_{2} \mathrm{~S}$ generation after cystathionine $\gamma$-lyase inhibitor treatment, a primary synthetase of $\mathrm{H}_{2} \mathrm{~S}$ in the gastrointestinal tract, significantly exacerbated DSS-induced colitis (Hirata et al., 2011; Flannigan et al., 2014). These results indicate that $\mathrm{H}_{2} \mathrm{~S}$ serves a beneficial role in DSS-induced colitis.

Compelling evidence in human and animal models has demonstrated that the generation of inflammatory cytokines and the inflammatory response in the gastrointestinal tract are involved in the progression of IBD (Beloqui et al., 2013; SánchezFidalgo et al., 2013; Scharl et al., 2013; McCann et al., 2015). In this study, we found that DSS exposure significantly up-regulated IL-1 $\beta$, IL-6, IL-10, IL-17, and TNF- $\alpha$ expression both in vivo and in vitro, whereas NaHS treatment alleviated this dysregulation; DSS treatment also decreased serum IgG and IgA, which was not alleviated by NaHS administration in our experiments. This may be because circulating immunoglobulins play an important role in the immune response: changes in immunoglobulins have been observed during the inflammatory response, suggesting their use as a potential therapy (Novokmet et al., 2014). Intransplantation-induced lung injury, NaHS injection has been demonstrated to inhibit the production of IL-1 $\beta$ and improve pulmonary function (Wu et al., 2013). Xu et al. (2015) reported that pre-treatment with NaHS ameliorates high glucoseinduced inflammation in $\mathrm{H} 9 \mathrm{c} 2$ cardiac cells, evidenced by the inhibition of IL-1 $\beta$, IL- 6 , and TNF- $\alpha$ expression. Furthermore, treatment with an $\mathrm{H}_{2} \mathrm{~S}$ donor in a rat model of non-erosive esophagitis markedly alleviated the inflammatory response and regulated serum IL-17 concentration (Zayachkivska et al., 2014). Thus, we speculate that $\mathrm{H}_{2} \mathrm{~S}$ may serve as an anti-inflammatory agent in DSS-induced inflammation in vivo and in vitro.

$\mathrm{NF}-\kappa \mathrm{B}$ has been considered to be a key proinflammatory transcription factor involved in the expression of various genes, including cytokines (Shori and Baba, 2015; Yin et al., 2015b). Under normal conditions, NF- $\kappa \mathrm{B}$ is sequestered in the cytoplasm via its inhibitory proteins, I $\mathrm{kBs}$ (Yin et al., $2013 b)$. Various reports have revealed the relation-

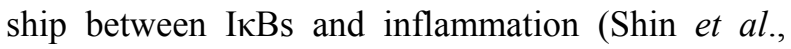
2012). Phosphorylation of I $\mathrm{B}$ s is associated with its degradation and NF- $\kappa \mathrm{B}$ activation (Yan and Polk, 1999). Compelling evidence suggests that NF- $\kappa B$ is 
activated in IBD and other inflammatory diseases (Cheon et al., 2006; Vinod and Guruvayoorappan, 2014; Rashti and Koohsari, 2015). Thus, inhibition of the NF- $\kappa \mathrm{B}$ signaling pathway has been considered to be a potential target for IBD therapy. In this study, both in vivo and in vitro data showed that DSS exposure activated the NF- $\mathrm{NB}$ signal and NaHS treatment significantly inhibited this activation. Similarly, Zhou et al. (2014) reported that $\mathrm{H}_{2} \mathrm{~S}$ exerts antiinflammatory effects by inhibiting NF- $\kappa \mathrm{B}$ signaling in high glucose-induced inflammation (McCann et al., 2015). As an upstream signal of NF- $\kappa \mathrm{B}$, TLR4/ Myd88 is also activated by DSS exposure and down-regulated by NaHS treatment, further demonstrating the anti-inflammatory effect of $\mathrm{H}_{2} \mathrm{~S}$.

In conclusion, the present study provides in vivo and in vitro evidence that $\mathrm{H}_{2} \mathrm{~S}$ derived from $\mathrm{NaHS}$ ameliorates the negative effects of DSS exposure in mice and Caco-2 cells and that this beneficial role may be associated with inhibition of the NF- $\mathrm{B}$ signaling pathway.

\section{Compliance with ethics guidelines}

$\mathrm{Xi}$ CHEN and Xi-shuang LIU declare that they have no conflict of interest.

All institutional and national guidelines for the care and use of laboratory animals were followed.

\section{References}

Beloqui, A., Coco, R., Alhouayek, M., et al., 2013. Budesonideloaded nanostructured lipid carriers reduce inflammation in murine DSS-induced colitis. Int. J. Pharm., 454(2): 775-783.

http://dx.doi.org/10.1016/j.ijpharm.2013.05.017

Benetti, L.R., Campos, D., Gurgueira, S.A., et al., 2013. Hydrogen sulfide inhibits oxidative stress in lungs from allergic mice in vivo. Eur. J. Pharmacol., 698(1-3):463-469. http://dx.doi.org/10.1016/j.ejphar.2012.11.025

Bhatia, M., 2015. $\mathrm{H}_{2} \mathrm{~S}$ and inflammation: an overview. In: Moore, P.K., Whiteman, M. (Eds.), Chemistry, Biochemistry and Pharmacology of Hydrogen Sulfide. Springer International Publishing, Switzerland, p.165-180. http://dx.doi.org/10.1007/978-3-319-18144-8_8

Cao, A.T., Yao, S., Stefka, A.T., et al., 2014. TLR4 regulates IFN- $\gamma$ and IL-17 production by both thymic and induced Foxp $3^{+} \mathrm{T}_{\text {regs }}$ during intestinal inflammation. J. Leukoc. Biol., 96(5):895-905. http://dx.doi.org/10.1189/jlb.3A0114-056RR

Cheon, J.H., Kim, J.S., Kim, J.M., et al., 2006. Plant sterol guggulsterone inhibits nuclear factor- $\mathrm{\kappa B}$ signaling in intestinal epithelial cells by blocking $\mathrm{I} \kappa \mathrm{B}$ kinase and ameliorates acute murine colitis. Inflamm. Bowel Dis., 12(12):1152-1161.

http://dx.doi.org/10.1097/01.mib.0000235830.94057.c6
Dubeau, M.F., Iacucci, M., Beck, P.L., et al., 2013. Druginduced inflammatory bowel disease and IBD-like conditions. Inflamm. Bowel Dis., 19(2):445-456. http://dx.doi.org/10.1002/ibd.22990

Eastep, J., Chen, G., 2015. The relationships of high-fat diet and metabolism of lipophilic vitamins. Integr. Food Nutr. Metab., 2(3):174-179. http://dx.doi.org/10.15761/IFNM.1000125

Flannigan, K.L., Agbor, T.A., Blackler, R.W., et al., 2014. Impaired hydrogen sulfide synthesis and IL-10 signaling underlie hyperhomocysteinemia-associated exacerbation of colitis. PNAS, 111(37):13559-13564. http://dx.doi.org/10.1073/pnas.1413390111

Furne, J.K., Suarez, F.L., Ewing, S.L., et al., 2000. Binding of hydrogen sulfide by bismuth does not prevent dextran sulfate-induced colitis in rats. Digest. Dis. Sci., 45(7): 1439-1443. http://dx.doi.org/10.1023/A:1005580709390

Gemici, B., Elsheikh, W., Feitosa, K.B., et al., 2015. $\mathrm{H}_{2} \mathrm{~S}-$ releasing drugs: anti-inflammatory, cytoprotective and chemopreventative potential. Nitric Oxide, 46:25-31. http://dx.doi.org/10.1016/j.niox.2014.11.010

Hirai, F., Matsui, T., 2015. Status of food intake and elemental nutrition in patients with Crohn's disease. Integr. Food Nutr. Metab., 2(2):148-150. http://dx.doi.org/10.15761/IFNM.1000118

Hirata, I., Naito, Y., Takagi, T., et al., 2011. Endogenous hydrogen sulfide is an anti-inflammatory molecule in dextran sodium sulfate-induced colitis in mice. Digest. Dis. Sci., 56(5):1379-1386. http://dx.doi.org/10.1007/s10620-010-1461-5

Howell, K., Yan, F., Tokich, A., et al., 2015. Iron sequestration is not the main mechanism in the inhibition of Staphylococcus aureus growth by cranberry phytochemicals. Integr. Food Nutr. Metab., 2(3):184-188. http://dx.doi.org/10.15761/IFNM.1000127

Kabil, O., Motl, N., Banerjee, R., 2014. $\mathrm{H}_{2} \mathrm{~S}$ and its role in redox signaling. Biochim. Biophys. Acta, 1844(8):1355-1366. http://dx.doi.org/10.1016/j.bbapap.2014.01.002

Kaplan, G.G., 2015. The global burden of IBD: from 2015 to 2025. Nat. Rev. Gastroenterol. Hepatol., 12:720-727. http://dx.doi.org/10.1038/nrgastro.2015.150

Kimura, Y., Kimura, H., 2004. Hydrogen sulfide protects neurons from oxidative stress. FASEB J., 18(10):1165-1167. http://dx.doi.org/10.1096/fj.04-1815fje

Lee, S.W., Hu, Y.S., Hu, L.F., et al., 2006. Hydrogen sulphide regulates calcium homeostasis in microglial cells. Glia, 54(2):116-124. http://dx.doi.org/10.1002/glia.20362

Liu, L., Xiao, Q.F., Zhang, Y.L., et al., 2014. A cross-sectional study of irritable bowel syndrome in nurses in China: prevalence and associated psychological and lifestyle factors. J. Zhejiang Univ.-Sci. B (Biomed. \& Biotechnol.), 15(6):590-597. http://dx.doi.org/10.1631/jzus.B1300159

Malago, J.J., Sangu, C.L., 2015. Intraperitoneal administration of butyrate prevents the severity of acetic acid colitis in rats. J. Zhejiang Univ.-Sci. B (Biomed. \& Biotechnol.), 
16(3):224-234.

http://dx.doi.org/10.1631/jzus.B1400191

McCann, M.J., Dalziel, J.E., Bibiloni, R., et al., 2015. An integrated approach to assessing the bio-activity of nutrients in vitro: the anti-oxidant effects of catechin and chlorogenic acid as an example. Integr. Food Nutr. Metab., 2(3):197-204.

http://dx.doi.org/10.15761/IFNM.1000130

Mikami, Y., Shibuya, N., Kimura, Y., et al., 2011. Hydrogen sulfide protects the retina from light-induced degeneration by the modulation of $\mathrm{Ca}^{2+}$ influx. J. Biol. Chem., 286(45): 39379-39386. http://dx.doi.org/10.1074/jbc.M111.298208

Mileva, S., Galunska, B., Gospodinova, M., et al., 2014. Vitamin D3 status in children with acute diarrhea. Integr. Food Nutr. Metab., 1(2):1-6. http://dx.doi.org/10.15761/IFNM.1000108

Nighot, P., Young, K., Nighot, M., et al., 2013. Chloride channel ClC-2 is a key factor in the development of DSS-induced murine colitis. Inflamm. Bowel Dis., 19(13): 2867-2877. http://dx.doi.org/10.1097/MIB.0b013e3182a82ae9

Novokmet, M., Lukic, E., Vuckovic, F., et al., 2014. Changes in IgG and total plasma protein glycomes in acute systemic inflammation. Sci. Rep., 4:4347. http://dx.doi.org/10.1038/srep04347

Pozsgai, G., Benko, R., Bartho, L., et al., 2015. Thermal spring water drinking attenuates dextran-sulfate-sodium-induced colitis in mice. Inflammopharmacology, 23(1):57-64. http://dx.doi.org/10.1007/s10787-014-0227-7

Rashti, Z., Koohsari, H., 2015. Antibacterial effects of supernatant of lactic acid bacteria isolated from different Dough's in Gorgan city in north of Iran. Integr. Food Nutr. Metab., 2(3):193-196. http://dx.doi.org/10.15761/IFNM.1000129

Sánchez-Fidalgo, S., Cardeno, A., Sanchez-Hidalgo, M., et al., 2013. Dietary extra virgin olive oil polyphenols supplementation modulates DSS-induced chronic colitis in mice. J. Nutr. Biochem., 24(7):1401-1413. http://dx.doi.org/10.1016/j.jnutbio.2012.11.008

Scharl, M., Vavricka, S.R., Rogler, G., 2013. Review: new anti-cytokines for IBD: what is in the pipeline? Curr. Drug Targets, 14(12):1405-1420. http://dx.doi.org/10.2174/13894501113149990159

Shimshoni, E., Yablecovitch, D., Baram, L., et al., 2015. ECM remodelling in IBD: innocent bystander or partner in crime? The emerging role of extracellular molecular events in sustaining intestinal inflammation. Gut, 64(3):367-372. http://dx.doi.org/10.1136/gutjnl-2014-308048

Shin, H.S., Kang, S.I., Yoon, S.A., et al., 2012. Sinensetin attenuates LPS-induced inflammation by regulating the protein level of IкB- $\alpha$. Biosci. Biotechnol. Biochem., 76(4):847-849.

http://dx.doi.org/10.1271/bbb.110908

Shori, A.B., Baba, A.S., 2015. Fermented milk derives bioactive peptides with antihypertensive effects. Integr. Food Nutr. Metab., 2(3):178-181.
http://dx.doi.org/10.15761/IFNM.1000126

Sun, X.F., Zhang, H., 2007. NFKB and NFKBI polymorphisms in relation to susceptibility of tumour and other diseases. Histol. Histopathol., 22(12):1387-1398.

Sunil, Y., Ramadori, G., Raddatzc, D., 2010. Influence of $\mathrm{NF \kappa B}$ inhibitors on IL-1 $\beta$-induced chemokine CXCL8 and -10 expression levels in intestinal epithelial cell lines: glucocorticoid ineffectiveness and paradoxical effect of PDTC. Int. J. Colorectal Dis., 25(3):323-333. http://dx.doi.org/10.1007/s00384-009-0847-3

Vinod, V.P., Guruvayoorappan, C., 2014. Protective effect of marine mangrove Rhizophora apiculata on acetic acid induced experimental colitis by regulating anti-oxidant enzymes, inflammatory mediators and nuclear factor- $\mathrm{\kappa B}$ subunits. Int. Immunopharmacol., 18(1):124-134. http://dx.doi.org/10.1016/j.intimp.2013.11.007

Vlantis, K., Polykratis, A., Welz, P.S., et al., 2015. TLRindependent anti-inflammatory function of intestinal epithelial TRAF6 signalling prevents DSS-induced colitis in mice. Gut, online. http://dx.doi.org/10.1136/gutjnl-2014-308323

Wang, W., Xia, T., Yu, X., 2015. Wogonin suppresses inflammatory response and maintains intestinal barrier function via TLR4-MyD88-TAK1-mediated NF- $\mathrm{kB}$ pathway in vitro. Inflamm. Res., 64(6):423-431. http://dx.doi.org/10.1007/s00011-015-0822-0

Watanabe, T., Sato, T., Miyazaki, M., et al., 2015. Effect of body composition intake with nano-lactic acid in rats. Integr. Food Nutr. Metab., 2(2):156-158. http://dx.doi.org/10.15761/IFNM.1000120

Wu, J., Wei, J., You, X., et al., 2013. Inhibition of hydrogen sulfide generation contributes to lung injury after experimental orthotopic lung transplantation. J. Surg. Res., 182(1):e25-e33. http://dx.doi.org/10.1016/j.jss.2012.09.028

$\mathrm{Xu}, \mathrm{W}$., Chen, J., Lin, J., et al., 2015. Exogenous $\mathrm{H}_{2} \mathrm{~S}$ protects $\mathrm{H} 9 \mathrm{c} 2$ cardiac cells against high glucose-induced injury and inflammation by inhibiting the activation of the NF- $\mathrm{kB}$ and IL-1 $\beta$ pathways. Int. J. Mol. Med., 35(1):177-186. http://dx.doi.org/10.3892/ijmm.2014.2007

Yan, F., Polk, D.B., 1999. Aminosalicylic acid inhibits IкB kinase $\alpha$ phosphorylation of $\mathrm{I} \kappa \mathrm{B} \alpha$ in mouse intestinal epithelial cells. J. Biol. Chem., 274(51):36631-36636. http://dx.doi.org/10.1074/jbc.274.51.36631

Yin, J., Ren, W., Liu, G., et al., 2013a. Birth oxidative stress and the development of an antioxidant system in newborn piglets. Free Radic. Res., 47(12):1027-1035. http://dx.doi.org/10.3109/10715762.2013.848277

Yin, J., Ren, W.K., Wu, X.S., et al., 2013b. Oxidative stressmediated signaling pathways: a review. J. Food Agric. Environ., 11(2):132-139.

Yin, J., Wu, M.M., Xiao, H., et al., 2014. Development of an antioxidant system after early weaning in piglets. J. Anim. Sci., 92(2):612-619. http://dx.doi.org/10.2527/jas.2013-6986

Yin, J., Liu, M., Ren, W., et al., 2015a. Effects of dietary supplementation with glutamate and aspartate on 
diquat-induced oxidative stress in piglets. PLOS ONE, 10(4):e0122893.

http://dx.doi.org/10.1371/journal.pone.0122893

Yin, J., Duan, J., Cui, Z., et al., 2015b. Hydrogen peroxideinduced oxidative stress activates NF- $\mathrm{KB}$ and Nrf2/Keap1 signals and triggers autophagy in piglets. $R S C A d v$., 5(20): 15479-15486. http://dx.doi.org/10.1039/C4RA13557A

Xu, X.J., Liu, L., Yao, S.K., 2016. Nerve growth factor and diarrhea-predominant irritable bowel syndrome (IBS-D): a potential therapeutic target? J. Zhejiang Univ.-Sci. B (Biomed. \& Biotechnol.), 17(1):1-9. http://dx.doi.org/10.1631/jzus.B1500181

Zayachkivska, O., Havryluk, O., Hrycevych, N., et al., 2014. Cytoprotective effects of hydrogen sulfide in novel rat models of non-erosive esophagitis. PLoS ONE, 9(10): e110688. http://dx.doi.org/10.1371/journal.pone.0110688

Zhang, P., Li, F., Wiegman, C.H., et al., 2015. Inhibitory effect of hydrogen sulfide on ozone-induced airway inflammation, oxidative stress, and bronchial hyperresponsiveness. Am. J. Resp. Cell Mol. Biol., 52(1):129-137. http://dx.doi.org/10.1165/rcmb.2013-0415OC

Zhou, X., Feng, Y., Zhan, Z., et al., 2014. Hydrogen sulfide alleviates diabetic nephropathy in a streptozotocininduced diabetic rat model. J. Biol. Chem., 289(42): 8827-8834.

http://dx.doi.org/10.1074/jbc.M114.596593

\section{中文概要}

题 目: 硫化氢通过抑制 NF-кB 信号通路对匍聚糖硫酸 钠（DSS）诱导的炎症反应起到缓解效果

目 的: 硫化氢 $\left(\mathrm{H}_{2} \mathrm{~S}\right)$ 具有抗氧化和抗炎反应的作用, 但是在 DSS 诱导的结肠炎模型中的研究鲜有报 道。因此, 本文采用小鼠和人结肠上皮细胞系 Caco-2 为实验模型, 研究了 $\mathrm{H}_{2} \mathrm{~S}$ 在 DSS 诱导的 炎症模型中的缓解效果。

创新点: (1) 本研究采用体内和体外模型分别对 $\mathrm{H}_{2} \mathrm{~S}$ 对 DSS 诱导的炎症缓解效果进行了验证, 结果发现 $\mathrm{H}_{2} \mathrm{~S}$ 具有抗炎作用; (2) 本研究发现 $\mathrm{H}_{2} \mathrm{~S}$ 能够抑 制核转录因子 $\kappa \mathrm{B}(\mathrm{NF}-\kappa \mathrm{B})$ 信号通路, 从而对炎 症起到缓解作用。

方 法: 采用 DSS 建立小鼠结肠炎模型, 腹腔注射 $\mathrm{H}_{2} \mathrm{~S}$ 供体硫化氢钠（NaHS）; 采用 DSS 诱导 Caco-2 炎症, 然后处理 $\mathrm{H}_{2} \mathrm{~S}$ 供体 NaHS。收集小鼠结肠 组织和细胞, 进行反转录聚合酶链反应 (RT-PCR) 和蛋白质免疫印迹法 (Western blot) 分析炎症基因和 NF- $\mathrm{\kappa B}$ 表达情况。

结 论: $\mathrm{H}_{2} \mathrm{~S}$ 对 DSS 诱导的体内和体外炎症反应具有一定 的缓解作用, 其机制可能是通过影响了 NF- $\mathrm{kB}$ 信号通路。

关键词: 硫化氢 $\left(\mathrm{H}_{2} \mathrm{~S}\right)$; 炎症反应; 核转录因子 $\kappa B(N F-\kappa B)$; 葡聚糖硫酸钠 (DSS) 